\title{
The Use of Technology in Dyslexia: An Analysis of Recent Trends
}

\author{
https://doi.org/10.3991/ijet.v15i05.11921 \\ Nilgun Degirmenci, Basak Baglama ${ }^{(\varpi)}$, Yucehan Yucesoy \\ Near East University, North Cyprus, Turkey \\ basak.baglama@neu.edu.tr
}

\begin{abstract}
Dyslexia is a common reading difficulty and bring difficulties in the academic and social lives of individuals. A good reader is expected to complete the reading task at a certain speed and understanding. Technological tools can be used to solve the problem for individuals who have problems in different dimensions of reading skills. Instructional technologies may be aimed at improving one's reading ability or facilitating reading action. This study aims to generate a comprehensive literature review and determine the current trends in the studies on dyslexia and technology in order to shed light for researchers and professionals working with individuals with dyslexia. This study was carried out to determine the potential and functional value of instructional technologies in learning processes of individuals with dyslexia through literature. A total number of 180 published documents in international databases through content analysis method. Results are presented with frequency and percentages in tables and figures. Results are discussed with relevant literature on dyslexia and technology and recommendations for further research and practices are provided.
\end{abstract}

Keywords-Dyslexia, technology, content analysis, learning difficulty.

\section{Introduction}

Individuals need education in order to survive and adapt to the outside world lifetime. However, in general education, all students in the classroom are expected to learn the same subject at the same speed and time [9]. One of the basic principles of developmental psychology is the principle of individual difference and each child is different from one another. These differences can be grouped as physical, cognitive and affective in general. Each child has his / her own physical structure and functions, learning and speed of learning in various fields and emotional characteristics. When these differences are within certain limits, students can benefit from general education services [18]; [5].

Learning involves permanent changes in behavior observed through repetition or experience. According to [24], individual differences affect the student's learning speed, level, interest and attention to learning, and the permanence of learning. However, individual differences occur due to the effect of heredity and environmental factors. Learning is a process that takes place in the human brain. The human brain is 
constantly stimulated from outside. These stimuli can be audible, visual, written, touch-related stimuli. Some of these stimuli are eliminated in the brain and some are processed [2] ; [16]. [17] stated that failure to receive the necessary stimuli indicates that there are problems at this stage of learning. For example, a child with problems in perceiving visual stimuli may confuse the letters $b$ and $d$, the numbers 6 and 9 . As it can be seen, learning occurs at the end of a complex process and deficiencies in different areas lead to different learning problems [11]; [13].

There are many factors that negatively affect the learning of school age children. One of the most important of these is specific learning difficulty. According to Diagnostic and Statistical Manual of Mental Disorders (DSM-5), it is defined as difficulties in listening, thinking, speaking, reading, writing and mathematical calculations arising from the effect of one or more psychological processes that are essential in understanding and using written and spoken language. It is divided into four classes as reading disorder (dyslexia), written expression disorder (dysgraphia), numerical (math) disorder (dyscalculia), learning disorders not otherwise classified [3] Furthermore, [4] defined learning disorders as the difficulty the child has in gaining and using literacy, mathematical and arithmetic skills, speaking, listening and reasoning skills.

Learning disorders are classified as reading, writing and mathematical learning difficulties and reading difficulties are commonly referred as dyslexia. Dyslexia is classified as a subtype of specific learning disorders. It is the most common learning disability associated with reading disorder and constitutes $80 \%$ of children diagnosed with learning difficulties [23]. Dyslexia is a neurobiological condition that affects the academic life of people from any environment, country or culture, regardless of the language or education system spoken [21]; [23]. Effective teaching and classroom management methods should be used in order to be successful for individuals with learning disorders. Individuals who have difficulty in different learning disciplines require individualized education. Special education services should be provided to support these students.

The most important process that will initiate dyslexia education is the process of diagnosing the individual. In this process, the individual with dyslexia is diagnosed and the level of dyslexia is determined and an individualized education plan is prepared. Especially early diagnosis has a very important role in the recruitment process of dyslexia for teaching functional skills [19]. Development of visual, auditory, tactile, perception; increasing attention and memory ability; development of motor skills as well as the development of three skills in speaking, listening, reading and writing; supporting the development of concepts and thinking should take place in this training. Teachers should be specialized in this way in order to realize the education of learning difficulties. Specialized teacher will determine the child's required skills as a result of evaluations and will make a program in that direction.

Typographical errors by individuals with dyslexia are very typical. In particular, the letters b, p, d are often confused because they are similar in shape and sound and mirror writing is seen. The child writes everything upside down or reads it backwards, punctuation errors are seen and their writings are often corrupted. School failure, school rejection, behavior problems, hyperactivity, migraine, enuresis, anxiety, de- 
pression, withdrawal may be other major problems which might arise in individuals with dyslexia. The severity and nature of these problems may vary depending on the child's individual characteristics [22]. Many individuals with dyslexia may have difficulty with any of the domains such as memory, ranking, time concepts, orientation, right-left separation and automate and manage concurrent activities. According to [1], difficulties occur in dyslexia could be divided into daily organization problems and operation and manipulation of symbols such as letters or numbers:

- Daily organization problems are associated with memory and organization skills. Individuals with dyslexia experience daily life difficulties because of their disorder.

- Operation and manipulation of symbols such as letters or numbers are primarily associated with academic skills which negatively affect school life of individuals with dyslexia.

It is expected that the use of technological devices for individuals with dyslexia will be useful in practice and facilitate their learning. When the results of technology use applications are examined, it is seen that there are positive changes in the learning outcomes of the students with dyslexia [26] ; [15]; [7]; [14]; [6]. Technological interventions which might be useful for individuals with dyslexia are alternative formal features (font, color), voice recognition, being an audible model, code analysis with visual cues and animations, vocabulary and letter recognition and writing awareness. It is necessary to know the learning behaviors of students with dyslexia in order to interpret which technologies are used in the learning processes of individuals with dyslexia. Providing education with technology support can increase opportunities for individuals with dyslexia who need individual support and specific strategies.

The fact that there is a rapid increase in the number of children diagnosed with dyslexia in a global context makes it more meaningful to continue scientific studies in this field throughout the world. It is really necessary to pay attention to this issue and to carry out the desired solutions to the educational environments and achieve the desired interventions. In recent years, there has been a significant increase in the number of printed publications, articles, papers and theses related to dyslexia. Considering the prevalent use of technology in dyslexia and increasing number of studies on this subject, it would be useful to make a comprehensive literature review on academic studies on this subject to determine the current trends. When the literature is examined, it is seen that number of studies examining the current trends in studies on dyslexia and technology, research is limited and it is also considered that providing such a review study would contribute to literature. Therefore, this study aimed to generate a comprehensive literature review and determine the current trends in the studies on dyslexia and technology in order to shed light for researchers and professionals working with individuals with dyslexia. In line with this general aim, answers to the following questions were sought in this study:

- What is the distribution of published documents on dyslexia and technology according to year of publication?

- What is the distribution of published documents on dyslexia and technology according to country? 
- What is the distribution of published documents on dyslexia and technology according to names and affiliations of the authors?

- What is the distribution of published documents on dyslexia and technology according to document type?

- What is the distribution of published documents on dyslexia and technology according to subject area?

- What is the distribution of published documents on dyslexia and technology according to research method?

\section{$2 \quad$ Method}

\section{$2.1 \quad$ Research model}

In this study, the content analysis was used as the method, since the studies carried out on dyslexia and technology were examined according to year of publication, country, names and affiliations of the authors, document type, subject area and research method. Content analysis is the summary, classification, comparison and numerical expression of text or other forms of content and messages with using scientific methods [8]. In this study, in addition to these aspects, it was preferred for the purpose of bringing the data together within the framework of certain concepts and themes and transforming it into a format that the reader will understand [10], [27].

\subsection{Data collection}

Firstly, in order to reach academic studies related to dyslexia and technology, ERIC and Scopus databases were searched by using the keywords "dyslexia" and "technology". After the screening, a total number of 180 studies were reached in which 125 of them were from Scopus and 55 from ERIC database.

\subsection{Data analysis}

The obtained studies were evaluated in terms of compliance with the purpose of the present study and 180 studies were examined based on previously determined content analysis criteria. The obtained data were analyzed with content analysis method and results were provided with frequencies in tables and figures.

\section{$3 \quad$ Result}

A total number of 180 published documents were analyzed based on the review of Scopus and ERIC databases. Results were interpreted according to content analysis criteria and discussed with relevant research from the literature. 


\subsection{Results of the published documents based on the year of publication}

\section{Year of Publication}

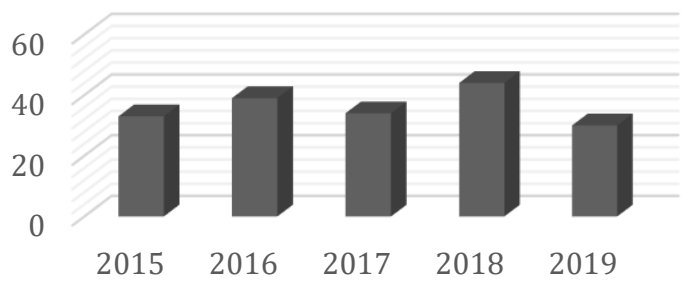

Fig. 1. Distribution of the published documents based on the year of publication

Figure 1 shows the results of the distribution of the articles based on the year of publication. The year of publication of the 180 studies examined within the scope of the study is shown in Figure 1. When Figure 1 is examined, it is seen that the most studies were conducted in 2018 and the least in 2015. As it can be seen, number of published documents showed a regular increase since 2015 and the highest number of publication is in 2018 with 44 publications. In other words, results revealed that articles on dyslexia and technology increased in the last 5 years.

\subsection{Results of the published documents based on the countries}

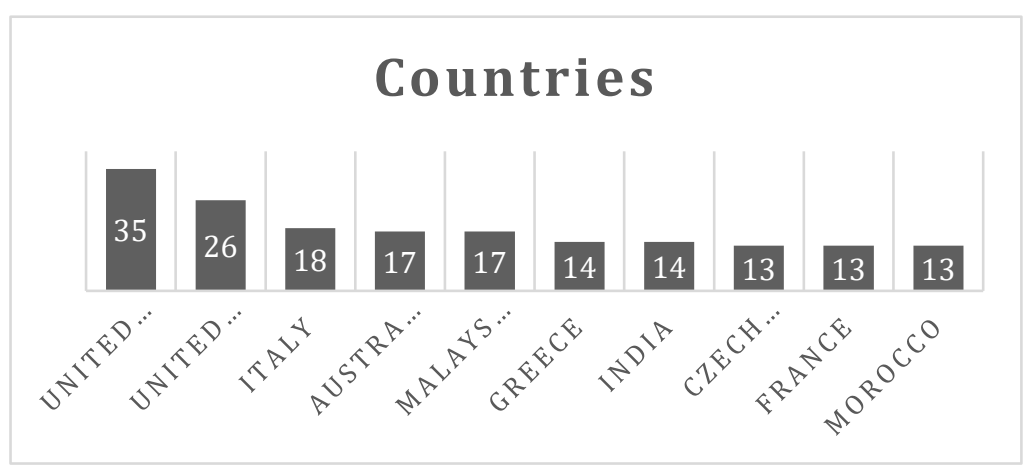

Fig. 2. Countries of the publications on dyslexia and technology

Distribution of the published documents based on the countries of the publications is shown in Figure 2. Results indicated that United Kingdom is the first country with 35 publications related with dyslexia and technology in Scopus and ERIC databases. This result is followed by United States, Italy, Australia, Malaysia, Greece, India, Czech Republic, France and Morocco were the other countries with high number of publications on dyslexia and technology. This result implied that publications on this 
subject is prevalent worldwide showing that there are high frequency of publications in 10 different countries.

\subsection{Results on the names and affiliations of the authors}

Results on the authors of the published documents and their affiliations were not demonstrated in table or figure because the frequencies were 1 or 2 and it would not be appropriate to show these results in a table or figure. Results showed that Chouaib Doukkali University in Morocco and Masaryk University in Czech Republic are the top two academic institutions as affiliations involved in the articles and the remained affiliations were only with one and two frequencies. These results suggested that there is no steady trend in the names and affiliations of authors in the articles on dyslexia and technology.

\subsection{Results of the published documents based on the document type}

Table 1. Document types of the published documents

\begin{tabular}{|l|c|c|}
\hline \multicolumn{1}{|c|}{ Document type } & f & \% \\
\hline Article & 125 & 69.44 \\
\hline Conference paper & 25 & 13.89 \\
\hline Review & 9 & 10.56 \\
\hline Book chapter & 9 & 10.56 \\
\hline Review & 6 & 3.33 \\
\hline Editorial & 5 & 2.77 \\
\hline Short Survey & 1 & 0.56 \\
\hline Total & 180 & 100 \\
\hline
\end{tabular}

Table 1 shows the document types of the published documents on dyslexia and technology examined in the study. As it can be seen from the table, majority of the published documents were articles ( $\mathrm{f}=125,69.44 \%$ ) out of 180 documents. Therefore, it can be said that authors prefer publishing research articles rather than other types of documents. It was also revealed that conference paper ( $\mathrm{f}=25,13.89 \%)$, book $(\mathrm{f}=11$, $6.11 \%$ ) and book chapter ( $\mathrm{f}=9,5.00)$ were also frequently observed document types. Therefore, it is understood that the researchers carried out more article types during these years. It is seen that the researchers focused more on paper type studies. 


\subsection{Results of the published documents based on the subject area}

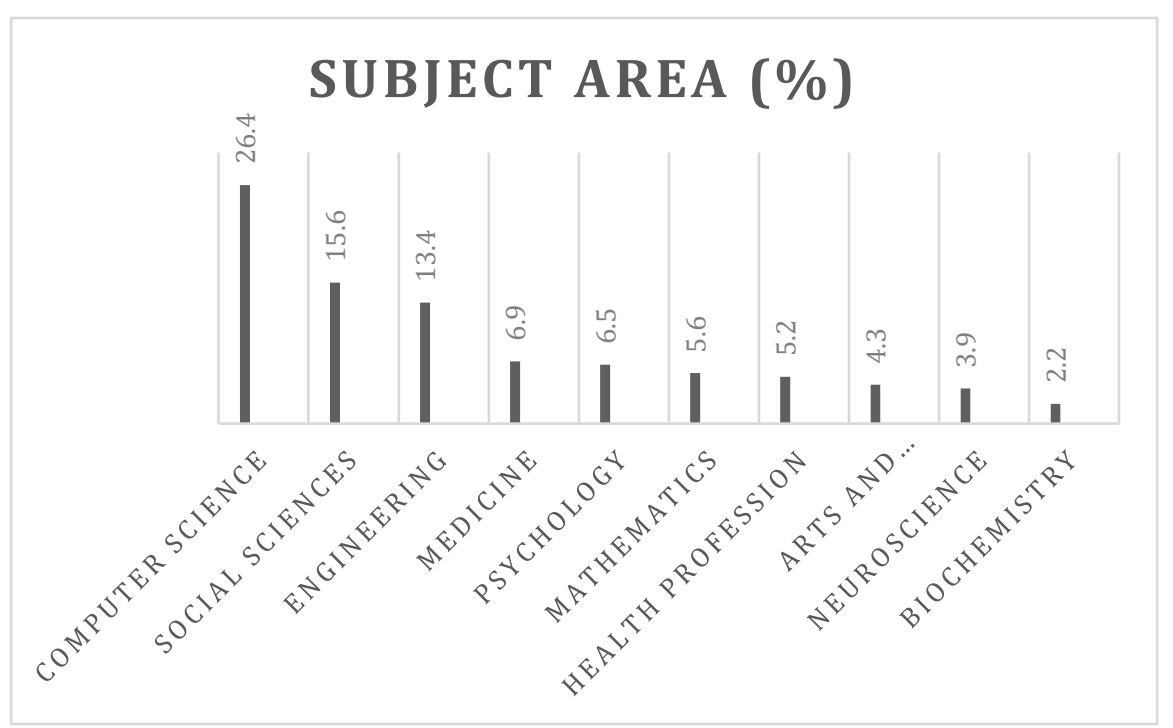

Fig. 3. Frequency distribution of the published documents based on the subject area

Figure 3 shows the results on the distribution of the published documents in percentages $(\%)$ based on the subject area. According to the results, the first five frequently studied subject areas are Computer Science $(26,4)$, Social Sciences (15.6), Engineering $(13,4)$, Medicine $(6,9)$ and Psychology $(6,5)$.

\subsection{Results of the published documents based on the research method}

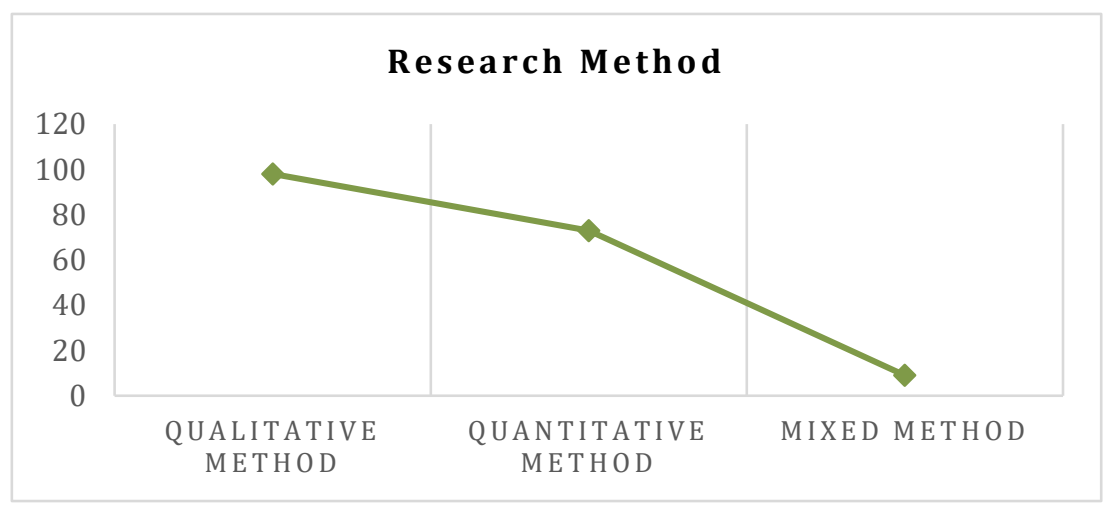

Fig. 4. Distribution of published documents based on the research method

Figure 4 shows the distribution of published documents based on the research method. Results revealed that qualitative research method is the most used research 
method $(n=98)$, this result is followed by quantitative research method $(n=73)$ and mixed research method $(n=9)$ in the published documents on dyslexia and technology.

\section{Discussion}

This study aims to generate a comprehensive literature review and determine the current trends in the studies on dyslexia and technology in order to shed light for researchers and professionals working with individuals with dyslexia. This study was carried out to determine the potential and functional value of instructional technologies in learning processes of individuals with dyslexia through literature. A total number of 180 published documents in international databases through content analysis method.

According to the results, it was revealed that articles on dyslexia and technology showed an increase throughout the years. When the literature is examined, it is seen that there are contradictory findings regarding this result. One study revealed that there are many studies showing the effectiveness of using assistive technologies for learning disorders [25]. In contrast, there are studies reporting that number of studies on dyslexia and technology is limited and more importance should be given for using technology to make interventions in dyslexia [15]; [12].

In addition to year of publication, studies on dyslexia were examined based on country, names and affiliations of the authors, document type, subject area and research method. Furthermore, results showed that United Kingdom, United States and Italy were the first three countries with higher publications on dyslexia and technology. Since there is limited number of similar studies providing a content analysis on dyslexia and technology, results of the present study were discussed with relevant literature on learning disorders. Results showed that Chouaib Doukkali University in Morocco and Masaryk University in Czech Republic are the top two academic institutions as affiliations involved in the articles and the remained affiliations were only with one and two frequencies.

According to the results, articles, conference papers and reviews were highly preferred by the researchers for publishing and the first five frequently studied subject areas are Computer Science, Social Sciences, Engineering, Medicine and Psychology. In a study, it was revealed that neuro-psychological properties, reading characteristics and supporting reading skills were the most studied research subject [20]. Results also showed that qualitative research method is the most used research method in the studies on dyslexia and technology. However, [20] showed that survey method was the most frequently studied research method in the studies on learning disorders.

In conclusion, this study provided a comprehensive literature review of the studies on dyslexia and technology and determine the current trends in the relevant studies. In line with the results of the study, following recommendations for further research and practices are provided:

- Other international academic databases might be analyzed in order to figure out the trends in published documents on dyslexia and technology.

- More studies need to focus on the potential function of technology on dyslexia. 
- This study might be replicated periodically in order to determine current trends and provide guidance for further research.

- Knowledge, skills and awareness on the benefits of using technology in dyslexia should be increased for professionals working in this field.

\section{$5 \quad$ References}

[1] Akyurek, G., \& Bumin, G. (2018). Disleksili cocuklarda ev okuryazarlik ortami ve aktivite rutinleri. Bozok Medical Journal, 8(03), 16-23. https://doi.org/10.16919/bozoktip.422204

[2] Altieri, N., Stevenson, R. A., Wallace, M. T., \& Wenger, M. J. (2015). Learning to associate auditory and visual stimuli: Behavioral and neural mechanisms. Brain Topography, 28(3), 479-493. https://doi.org/10.1007/s10548-013-0333-7

[3] American Psychiatric Association, (2013). Diagnostic and statistical manual of mental disorders (5th ed.) Washington, DC: Author.

[4] Balci, E. (2017). Dyslexia: Definition, classification and symptoms. SDU International Journal of Educational Studies, 4(2), 166-180.

[5] Balzarotti, S., Biassoni, F., Villani, D., Prunas, A., \& Velotti, P. (2016). Individual differences in cognitive emotion regulation: Implications for subjective and psychological wellbeing. Journal of Happiness Studies, 17(1), 125-143. https://doi.org/10.1007/s10902-0149587-3

[6] Caute, A., Cruice, M., Marshall, J., Monnelly, K., Wilson, S., \& Woolf, C. (2018). Assistive technology approaches to reading therapy for people with acquired dyslexia. Aphasiology, 32(sup1), 40-42. https://doi.org/10.1080/02687038.2018.1489119

[7] Cidrim, L.,\& Madeiro, F. (2017). Information and Communication Technology (ICT) applied to dyslexia: literature review. Revista CEFAC, 19(1), 99-108. https://doi.org/10.15 90/1982-0216201719610317

[8] Cohen, L., Manion, L., \& Morrison, K. (2007). Research methods in education (6th ed.). New York, NY: Routledge.

[9] Demirel, O., \& Kaya, Z. (2017). Introduction to education science. Ankara: Pegem Publishing.

[10] Fraenkel, J. R.,\& Wallen, N. (2000). How to design and evaluate research in education (4th ed.). NY: McGraw-Hill.

[11] Ercan, E. S., \& Aydin, C. (2014). Attention deficit and hyperactivity disorder for parents and teachers (5th edition). Istanbul: Gendas Publishing.

[12] Gorgun, B.,\& Melekoglu, M. A. (2019). Turkiye'de ozel ogrenme guclugu alaninda yapilan calismalarin incelenmesi. Sakarya University Journal of Education, 9(1), 83-106.

[13] Horowitz-Kraus, T. (2016). Improvement of the error-detection mechanism in adults with dyslexia following reading acceleration training. Dyslexia, 22(2), 173-189. https://doi.org/ $10.1002 /$ dys. 1523

[14] Jing, C. T.,\& Chen, C. J. (2017). A research review: How technology helps to improve the learning process of learners with dyslexia. Journal of Cognitive Sciences and Human Development, 2(2), 26-43. https://doi.org/10.33736/jcshd.510.2017

[15] Ozbek, A. B. (2015). Use of technology in reading difficulty interventions. Journal of Education \& Special Education Technology, 1(1), 48-53.

[16] Lin, T. C. E.,\& Honey, R. C. (2016). Learning about stimuli that are present and those that are not: Separable acquisition processes for direct and mediated learning. The Wiley Handbook on the Cognitive Neuroscience of Learning, 16, 69-85. https://doi.org/10.1002/ 9781118650813.ch4 
[17] Nicolson, R. I.,\& Fawcett, A. J. (2018). Procedural learning, dyslexia and delayed neural commitment. In Reading and Dyslexia(pp. 235-269). Cham: Springer. https://doi.org/10. 1007/978-3-319-90805-2_12

[18] Norwich, B. (2002). Education, inclusion and individual differences: Recognising and resolving dilemmas. British Journal of Educational Studies, 50(4), 482-502. https://doi.or $\mathrm{g} / 10.1111 / 1467-8527 . \mathrm{t} 01-1-00215$

[19] Ozernov-Palchik, O.,\& Gaab, N. (2016). Tackling the early identification of dyslexia with the help of neuroimaging. Perspectives on Language and Literacy, 42(1), 11-22.

[20] Ozkardes, O. G. (2013). Turkiye'de ozel ogrenme guclugune iliskin yapilan arastirmalarin betimsel analizi. Bogazici Universitesi Egitim Dergisi, 30(2), 123-153. https://doi.org/10. 1501/ozlegt 0000000084

[21] Parrilla, R. K.,\& Protopapas, A. (2017). Dyslexia and word reading problems.Holland: JohnBenjamin Publication.

[22] Proctor, C. M., Mather, N., Stephens-Pisecco, T. L., \& Jaffe, L. E. (2017). Assessment of Dyslexia. Communique, 46(3), 1-20.

[23] Seidenberg, M. S. (2005). Connectionist models of word reading. Current Directions in Psychological Science, 14(5), 238-242. https://doi.org/10.1111/j.0963-7214.2005.00372.x

[24] Spiro, R. J., Bruce, B. C., \& Brewer, W. F. (2017). Theoretical issues in reading comprehension: Perspectives from cognitive psychology, linguistics, artificial intelligence and education. US: Routledge. https://doi.org/10.4324/9781315107493

[25] Svensson, I., Nordström, T., Lindeblad, E., Gustafson, S., Björn, M., Sand, C., \& Nilsson, S. (2019). Effects of assistive technology for students with reading and writing disabilities. Disability and Rehabilitation: Assistive Technology, 14(7), 1-13. https://doi.org/10.1080/ $\underline{17483107.2019 .1646821}$

[26] Wagner, D. A., Castillo, N. M., Murphy, K. M., Crofton, M., \& Zahra, F. T. (2014). Mobiles for literacy in developing countries: An effectiveness framework. Prospects, 44(1), 119-132. https://doi.org/10.1007/s11125-014-9298-x

[27] Yildirim, A., \& Simsek, H. (2005). Sosyal bilimlerde nitel arastirma yontemleri. Ankara: Seckin Publishing.

\section{Authors}

Nilgun Degirmenci, studies her postgraduate degree at Department of Special Education, Atatürk Faculty of Education, Near East University. , nilgun.degirmenci@o $\underline{\text { utlook.com.tr }}$

Basak Baglama, currently works at Department of Special Education, Atatürk Faculty of Education, Near East University. Her research interests include technology assisted teaching in special education, teaching mathematics, intellectual disability and learning difficulty.

Yucehan Yucesoy, works at Department of Classroom Teaching, Atatürk Faculty of Education, Near East University. He studies instructional technology, art education and material design. yucehan.yucesoy @neu.edu.tr

Article submitted 2019-10-19. Resubmitted 2019-11-17. Final acceptance 2019-11-23. Final version published as submitted by the authors. 